\title{
Komfortabel für Anwender und Patient
}

COMFOUR ist das neu entwickelte System von CAMLOG für okklusal verschraubte Versorgungen (zum 1. Oktober 2015 für das CAMLOG-Implantatsystem; für das CONELOG-Implantatsystem ab Januar 2016 verfügbar) im zahnlosen oder teilbezahnten Kiefer. Durch die vielen technischen Highlights sind mit dem neuene

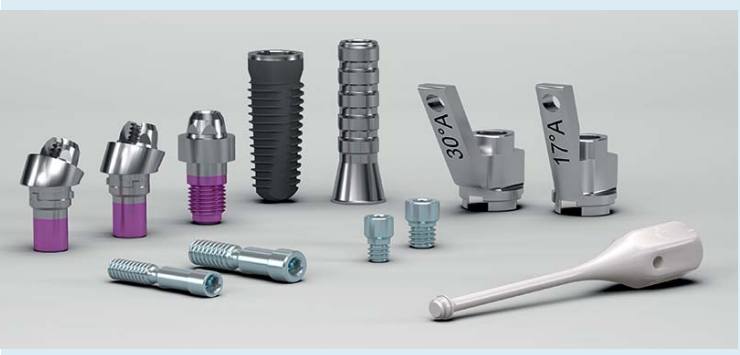

System gleich mehrere Behandlungskonzepte realisierbar. Neben okklusal verschraubten Brücken für Sofort- und Spätversorgungen auf in der Regel 4 oder 6 Implantaten, erlaubt das multioptionale System auch Steg- und Einzelzahnversorgungen auf geraden und abgewinkelten Stegaufbauten. Das System ist zeitsparend und flexibel in der Anwendung. Die $17^{\circ}$ und $30^{\circ}$ abgewinkelte Stegaufbauten sind besonders im subgingivalen Bereich schmal gestaltet, sodass für die periimplantären Gewebe viel Platz bleibt. Die Aufbauten sind als Typ A und Typ B ( $60^{\circ}$ versetzte Nocken) erhältlich. Die sterilen Stegaufbauten können unmittelbar nach der Operation eingebracht und entweder provisorisch versorgt oder mit einer Heilkappe verschlossen werden. Die gewinkelten Stegaufbauten werden mithilfe des vormontierten flexiblen Handgriffs sicher aus der Verpackung entnommen, damit in den Mund übertragen und können exakt positioniert werden. Die M1.6 Prothetikschraube des COMFOUR-Systems bietet ein Mehr an Stabilität. Hilfreiche Zusatzkomponenten sind die Titankappen für die provisorische und definitive Versorgung. Mit den Scankappen für Stegaufbauten wurde eine Schnittstelle in die digitale Fertigung geschaffen. So können Gerüste und Stege über DEDICAM gefertigt werden.

Nach einer Pressemitteilung der CAMLOG Vertriebs GmbH, Wimsheim info.de@camlog.com

www.camlog.de 